\title{
Celecoxib as an adjuvant to chemotherapy for patients with metastatic colorectal cancer
}

\author{
A randomized controlled clinical study
}

Tarek M. Mostafa, PhD, Mohamed A. Alm El-Din, MD, PhD, Amira R. Rashdan, BSc.

\begin{abstract}
الأهداف : تقييم مدى فاعليه وأمان دواء السيليكو كسيب كمضاد لانتشارالورم المان

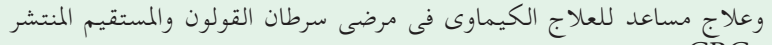

( $\mathrm{CRC}$ )

المنهجية: تضمنت هذه الدراسة السريرية العشوائية الخاضعة للرقابة 54 مريضًا

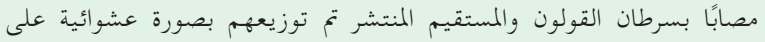

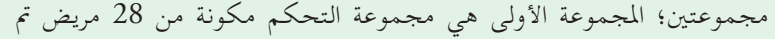

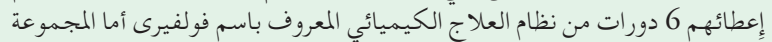

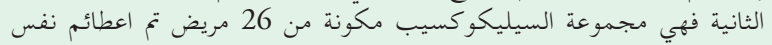

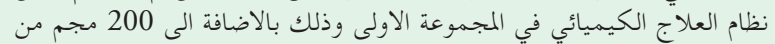

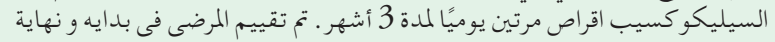

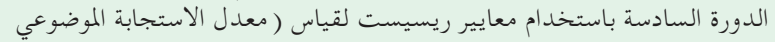

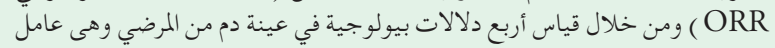

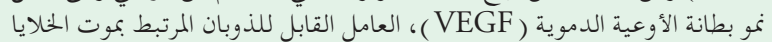

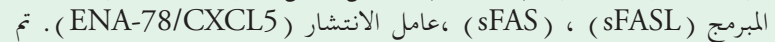

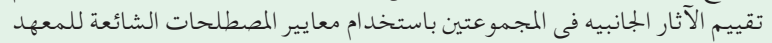

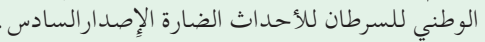

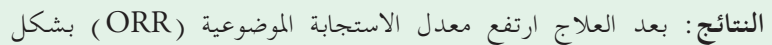

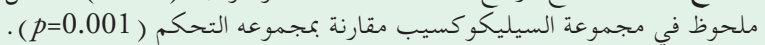

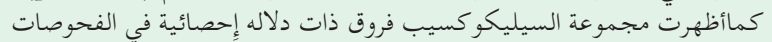

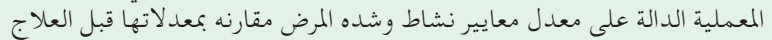

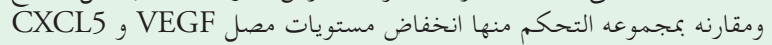

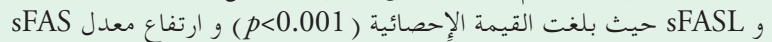
FASL بشكل إحصائي ( FASL

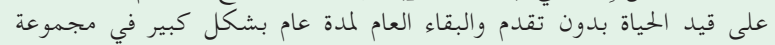

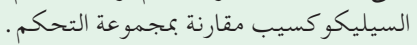

الحلاصة : قد يمثل السيليكو كسيب عاملاً مساعدًا واعدًا للعلاج الكيميائي

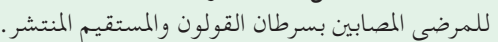

Objectives: To investigate the anti-tumor activity and tolerability of celecoxib as an adjuvant therapy for patients with metastatic colorectal cancer (CRC).

Methods: In this randomized controlled study, 54 patients with metastatic CRC were randomized into 2 groups; the control group $(n=28)$ which received 6 cycles of folinic acid, fluorouracil and irinotecan (FOLFIRI) regimen (5-flourouracil, leucovorin, irinotecan), and the celecoxib group $(\mathrm{n}=26)$ which received 6 cycles of FOLFIRI regimen plus celecoxib
$200 \mathrm{mg}$ twice daily. The study duration was 3 months. Patients were assessed at baseline and at the end of intervention through the Response Evaluation Criteria in Solid Tumors objective response rate (ORR) and through evaluating the serum concentrations of vascular endothelial growth factor (VEGF), soluble factor-related apoptosis (sFAS), sFAS ligand (sFASL), and epithelial neutrophil-activating peptide -78 (ENA-78/CXCL5). Common Terminology Criteria for Adverse Events version 6.0 was used for evaluating drug-related toxicity.

Results: After intervention, celecoxib/FOLFIRI arm showed significant elevation in ORR as compared to FOLFIRI arm $(p=0.001)$. As compared to FOLFIRI arm, celecoxib/FOLFIRI arm showed significantly lower VEGF $(p<0.001)$, CXCL5 $(p<0.001)$, and sFASL $(p<0.001)$ serum levels and significantly higher sFAS serum level and $s F A S / F A S L$ ratio $(p<0.001)$. Furthermore, celecoxib/FOLFIRI arm showed significantly higher progression-free survival and one-year overall survival when compared to FOLFIRI arm.

Conclusion: Celecoxib plus chemotherapy may represent an effective and safe synergetic protocol for patients with metastatic CRC.

Clinicaltrial.gov ID:NCT03645187

Keywords: colorectal cancer, celecoxib, RECIST, VEGF, CXCL5, sFAS/FASL

Saudi Med J 2022; Vol. 43 (1): 37-44 doi: 10.15537/smj.2022.43.1.20210574

From the Department of Clinical Pharmacy (Mostafa, Rashdan), Faculty of Pharmacy; and from the Department of Clinical Oncology (Alm El-Din), Faculty of Medicine, Tanta University, Tanta, Egypt.

Received 15th July 2021. Accepted 3rd November 2021.

Address correspondence and reprint request to: Dr. Amira R. Rashdan, Clinical Pharmacy Department, Faculty of Pharmacy, Tanta University, Tanta, Egypt.E-mail:amira.rashdan@pharm.tanta.edu.eg ORCID ID: https://orcid.org/0000-0003-3156-6771 
$\mathrm{C}$ olorectal cancer (CRC) is the third most common cancer and the second leading cause of malignancyrelated mortality. Approximately one million people are diagnosed and 100,000 deaths or more are recorded annually worldwide. ${ }^{1}$

Despite considerable advances in the early detection and management of patients with CRC, the long-term overall survival has not improved notably over the past decades. ${ }^{2}$ Although, chemotherapy is a crucial approach for CRC treatment, some patients show disease progression despite the implication of 2 different chemotherapeutic agents and consequently, they have become narrow therapeutic options. Hence, it seems urgent to search for new therapeutic agents that are capable of fighting CRC cells and enhance the chemotherapy effectiveness. ${ }^{3,4}$ Recently, a new strategy based on the development of effective cancer treatment via the repositioning of traditional non-anticancer drugs depending on the available knowledge on their mode of action, pharmacokinetics and tolerability which in turn, can facilitate their implications in clinical settings. ${ }^{5}$

The correlation between inflammation with both cancer growth and metastasis is not a novelty. It has been proposed that, infiltration of tumor with inflammatory cells is accompanied by oncogenesis via promoting division, growth, survival, and migration of malignant cells. Additionally, malignant cells commandeer several chemokines as signaling molecules for their growth. ${ }^{6}$ These former findings provide support for the implication of anti-inflammatory medications including cyclooxygenase-2 (COX-2) inhibitors for the prevention and the management of cancer. In addition, it was reported that the over-expression of COX-2 is linked to poor outcome in many types of human cancers.?

There are many animal and human studies directed at evaluating the antineoplastic effect of celecoxib. Preclinical ones revealed that, implication of celecoxib resulted in reduction of implanted cancer cell growth, decrease in angiogenesis, and fighting of metastases. ${ }^{8}$ The clinical trials conducted recently to evaluate the role of celecoxib in enhancing the effect of chemotherapy showed either modest effect or lack of effect. ${ }^{9-11}$ Thus, additional clinical trials on the anti-tumor efficacy of celecoxib are still required to provide results oriented clinical data. ${ }^{?}$

Therefore, we aimed at evaluating the anti-tumor and chemo-sensitizing effects of celecoxib in patients

Disclosure. Authors have no conflict of interests, and the work was not supported or funded by any drug company. with metastatic CRC via Response Evaluation Criteria in Solid Tumors (RECIST) and to assess the serum levels of vascular endothelial growth factor (VEGF), soluble factor-related apoptosis (sFAS), sFAS ligand (sFASL), and epithelial neutrophil-activating peptide -78 (ENA-78/CXCL5).

Methods. In this randomized open labeled controlled prospective study, we recruited patients with histologically confirmed diagnosis of metastatic CRC from the Oncology Department of Tanta University Hospital, Tanta, Egypt, between October 2018 and July 2020.

The inclusion criteria were: both gender; age $\geq 18$ years old; performance status 0-2 according to the Eastern Cooperative Oncology Group (ECOG); patients with adequate hematologic parameters (white blood cell count $\geq 3000 / \mathrm{mm}^{3}$, granulocytes $\geq 1500 / \mathrm{mm}^{3}$, platelets $\geq 100,000 / \mathrm{mm}^{3}$, hemoglobin $\geq 8 \mathrm{gm} / \mathrm{l}$ ), adequate renal functions (creatinine clearance $\geq 50 \mathrm{ml} / \mathrm{min}$ ), and adequate hepatic functions (bilirubin $\leq 1.5 \mathrm{mg} / \mathrm{dL}$, albumin $\geq 3 \mathrm{~g} / \mathrm{dL}$ ). The exclusion criteria were: patients with significant cardiovascular or cerebrovascular diseases, clotting disorders, ascites, hemorrhage, malabsorption, extensive bowel resections, active peptic ulcer, brain metastases, infection and psychiatric disorders; patients on chronic use of corticosteroids or those on concomitant intake of investigational medications; pregnant and lactating women; patients with previous allergy to non-steroidal anti-inflammatory drugs (NSAIDs) or sulfonamides. Fifty-four patients were selected randomized using sealed envelopes method into the 2 study groups: the control group $(n=28)$ which received folinic acid, fluorouracil and irinotecan (FOLFIRI) regimen for 6 cycles (on day one, irinotecan $180 \mathrm{mg} / \mathrm{m}^{2}$ IV over 30-90 min is taken simultaneously with leucovorin $400 \mathrm{mg} / \mathrm{m}^{2}$ IV plus 5 -FU $400 \mathrm{mg} / \mathrm{m}^{2}$ IV bolus, then $1200 \mathrm{mg} / \mathrm{m}^{2} /$ day of 5 -FU continuous infusion for 2 days [total $2400 \mathrm{mg} / \mathrm{m}^{2}$ over $46-48$ hours], repeated every 2 weeks) and celecoxib group $(n=26)$ which received the same chemotherapeutic regimen plus celecoxib $200 \mathrm{mg}$ twice daily. The study duration was 3 months. We instructed patients on NSAIDs to discontinue their medications at least 2 weeks prior to the first dose of celecoxib.

The study was conducted following the Ethical Standards of Helsinki Declaration in 1964 and its later amendments. The Research Ethical Committee of Tanta University, Tanta, Eygpt, approved the study protocol (approval code: 32371/06/18). All enrolled patients gave their written informed consent.

Demographic data (age, gender, and medication history) was collected for all patients. Patients were also 
submitted to a physical examination and anthropometric measurements (weight, height with calculation of body mass index $\left(\mathrm{BMI}=\left[\right.\right.$ weight $(\mathrm{kg}) /$ height $\left.\left.\left(\mathrm{m}^{2}\right)\right]\right)$.

We assessed tumor responses using the RECIST. ${ }^{12}$ Tumor response is characterized by both objective response rate (ORR) and disease control rate (DCR). Objective response rate is the percentage of patients who shows complete responses (CR) and partial response towards the treatment. Disease control rate is the sum of complete responses, partial response, and stable disease. We repeated assessments for 4 weeks or more after recording the response criteria to confirm complete and partial responses, and at least 7 weeks after initial assessment to confirm stable disease.

Before interventions and after the $6^{\text {th }}$ cycle, we withdrawn blood samples from all participants by antecubital venipuncture between 8:00-11:00 a.m. Blood samples were centrifuged at $3000 \mathrm{rpm}$ for 15 minutes to separate sera. Sera were kept at deep freeze $\left(-80^{\circ} \mathrm{C}\right)$ until the analysis of serum concentrations (VEGF, sFAS, sFASL, and ENA-78/CXCL5) was completed, using double-antibody sandwich enzyme-linked immuno-sorbent assay kits (Sun Red Biotechnology Co., China; Catalog No. 201-12-0081, 201-12-1839, 201-12-1838 and 201-12-0132).

During the study duration, celecoxib tablets were supplied at biweekly intervals and we assessed participants adherence through medication refilling rate. Participants were followed-up weekly by phone calls and during biweekly clinic visits to assess their compliance and to report any drug associated side effects. We assessed drug-related toxicity according to the Common Terminology Criteria for Adverse Events, version 6 (CTCAE v 6.0).

We carried out gradual follow up for one year to assess the progression free survival (PFS) and the overall survival (OS).

The primary outcome was the change in ORR which was assessed in both arms at the end of the $6^{\text {th }}$ cycle using the RECIST criteria. The secondary outcome was the changes in serum levels of biological biomarkers (VEGF, sFAS, sFASL, and CXCL5) and tumor markers.

Statistical analysis. Statistical Package for the Social Sciences, version 22.0 (IBM Corp., Armonk, NY, USA) was used for all statistical analysis. Unpaired and paired student t-tests were used to compare the parametric data. The Kaplan-Meier method was applied to assess PFS and OS. A 95\% exact binomial confidence interval was used to determine median PFS and OS. Categorical data was analyzed by Fisher's exact test and log-rank test was used for survival analysis. A $p$-value $<0.05$ was considered significant.
Results. Out of 134 patients with metastatic CRC assessed for eligibility, 73 patients were excluded (62 patients did not meet the inclusion criteria and 11 patients declined to participate). Therefore, 61 patients were selected randomly into the 2 study groups including the FOLFIRI arm (control group; $n=31$ ) and the celecoxib/FOLFIRI arm $(n=30)$. During the course of the study, 7 participants in both groups were dropped out secondary to missed data $(n=2)$, change in chemotherapy regimen $(n=3)$, non-adherence to celecoxib $(n=1)$, and death in FOLFIRI $\operatorname{arm}(n=1)$. The final analysis thus included 54 patients (28 patients in FOLFIRI arm and 26 patients in celecoxib/FOLFIRI arm). Participants' flowchart is provided in Figure 1.

A statistically non-significant variation was observed between the 2 groups regarding gender, weight, height, BMI, site of primary tumor, and metastatic sites $(p>0.05)$ as presented in Table 1 .

The serum levels of the measured biological markers were statistically similar at baseline. After the $6^{\text {th }}$ chemotherapeutic cycle, tumor markers (carcinoembryonic antigen and cancer antigen 19-9) showed a statistically significant decline in celecoxib/ FOLFIRI arm $(28.8 \%$ versus $90.1 \% ; \quad p<0.001)$ compared to the FOLFIRI regimen alone $(47 \%$ versus $139.5 \% ; p<0.001)$. The mean serum levels of VEGF, CXCL5, and sFASL were significantly lower in celecoxib/FOLFIRI arm than FOLFIRI arm alone (1533.09 ng/l versus $2261.15 \mathrm{ng} / \mathrm{l}, \quad p<0.001$; $51.19 \mathrm{pg} / \mathrm{ml}$ versus $93.43 \mathrm{pg} / \mathrm{ml}, \quad p<0.001 ; 9.24$ $\mathrm{ng} / \mathrm{ml}$ versus $16.51 \mathrm{ng} / \mathrm{ml}, p<0.001$. On the other hand, the mean serum level of sFAS and sFAS/FASL ratio were significantly increased after the $6^{\text {th }}$ cycle in celecoxib/FOLFIRI arm group $(65.1 \mathrm{ng} / \mathrm{ml}$ versus $48.51 \mathrm{ng} / \mathrm{ml} ; p<0.001)$ as compared to the FOLFIRI group $(8.17 \mathrm{ng} / \mathrm{ml}$ versus $3.03 \mathrm{ng} / \mathrm{ml} ; p<0.0001)$. These former results are provided in Table 2 \& Figure 2.

After intervention, one (3.9\%) patient in the celecoxib/FOLFIRI arm showed CR and 15 (57.7\%) patients exhibited PRs. Furthermore, 5 (19.2\%) patients showed stable disease, and 5 (19.2\%) patients developed progressive disease. After the $6^{\text {th }}$ cycle, ORR and DCR showed significant increase in celecoxib/FOLFIRI $\operatorname{arm}(61.5 \%$ versus $17.9 \%, p=0.001)$ as compared to the FOLFIRI arm (80.8\% versus $39.3 \%$; $p=0.002)$. Progression free survival and one-year OS were significantly increased in celecoxib/FOLFIRI arm (30 versus 23 weeks, $p=0.0036$ ) as compared to FOLFIRI regimen alone (12 versus 8 months, $p=0.0424)$. The results are provided in Table 3.

All patients were evaluated for drugs related toxicity according to the CTCAE v 6.0. Overall, the reported 


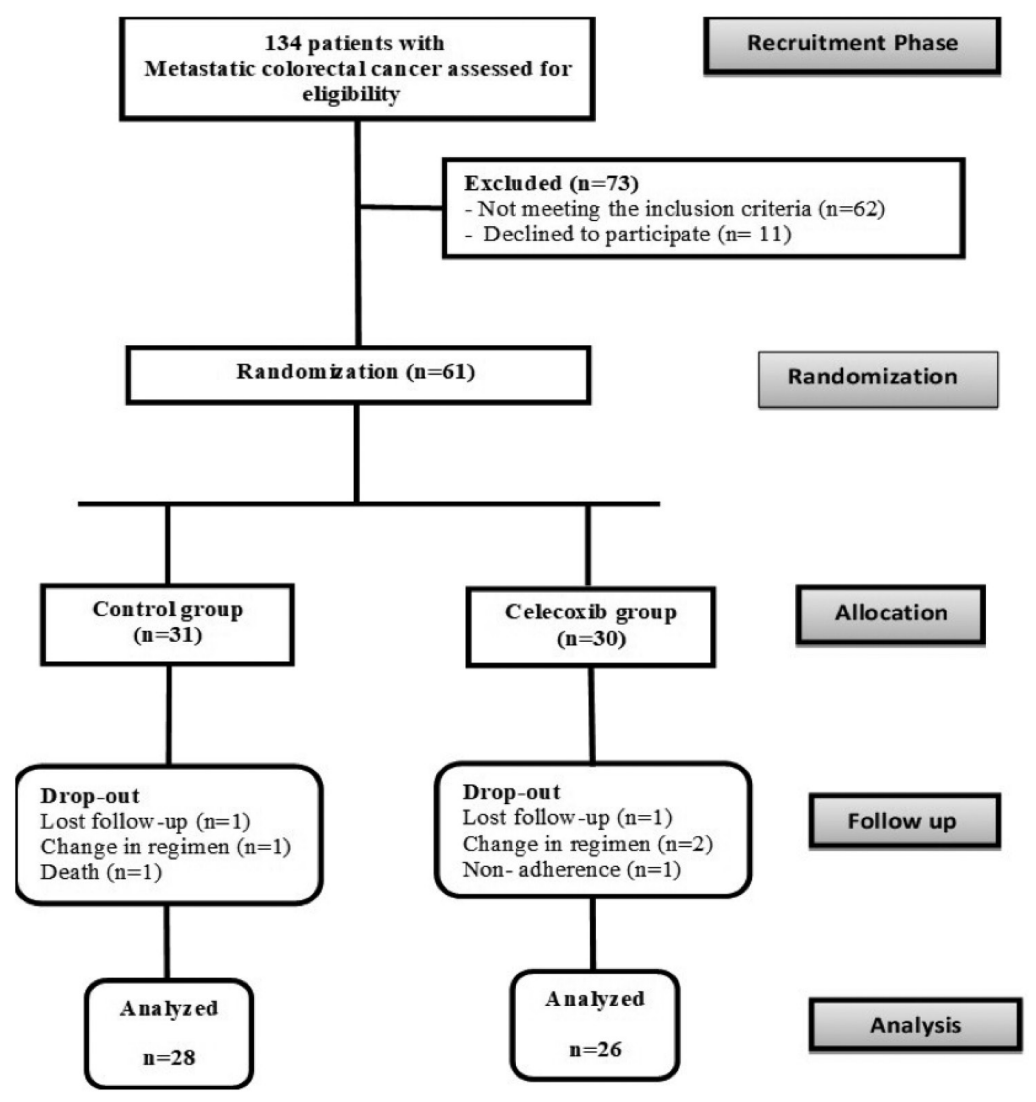

Figure 1 - Consolidated standards of reporting trials (CONSORT) diagram showing the disposition of all subjects screened for the study.

Table 1 - Demographic and clinical data of the study participants.

\begin{tabular}{|c|c|c|c|}
\hline \multirow[t]{2}{*}{ Parameters } & $\begin{array}{c}\text { Control group } \\
(n=28)\end{array}$ & $\begin{array}{l}\text { Celecoxib group } \\
\qquad(\mathrm{n}=26)\end{array}$ & \multirow[t]{2}{*}{$P$-value } \\
\hline & \multicolumn{2}{|c|}{$\mathbf{n}(\%)$} & \\
\hline \multicolumn{4}{|l|}{ Gender } \\
\hline $\begin{array}{l}\text { Male } \\
\text { Female }\end{array}$ & $\begin{array}{c}9(32.1) \\
19(67.8)\end{array}$ & $\begin{array}{c}9(34.6) \\
17(65.3)\end{array}$ & 0.847 \\
\hline Age (years), mean $\pm S D$ & $42.04 \pm 8.95$ & $45.92 \pm 5.07$ & 0.058 \\
\hline Weight $(\mathrm{kg})$, mean $\pm \mathrm{SD}$ & $72.39 \pm 4.13$ & $72.26 \pm 4.29$ & 0.915 \\
\hline Height $(\mathrm{cm})$, mean \pm SD & $161.34 \pm 1.49$ & $162.96 \pm 4.56$ & 0.084 \\
\hline BMI $\left(\mathrm{kg} / \mathrm{m}^{2}\right)$, mean $\pm \mathrm{SD}$ & $27.8 \pm 1.49$ & $27.25 \pm 1.84$ & 0.227 \\
\hline \multicolumn{4}{|l|}{ Primary tumor } \\
\hline $\begin{array}{l}\text { Colon } \\
\text { Rectum }\end{array}$ & $\begin{array}{l}21(75) \\
7(25)\end{array}$ & $\begin{array}{c}23(88.5) \\
3(11.5)\end{array}$ & 0.203 \\
\hline \multicolumn{4}{|l|}{ Metastatic site } \\
\hline $\begin{array}{l}\text { Liver } \\
\text { Others }\end{array}$ & $\begin{array}{l}15(53.6) \\
13(46.4)\end{array}$ & $\begin{array}{l}19(73.1) \\
7(26.9)\end{array}$ & 0.138 \\
\hline \multicolumn{4}{|c|}{ BMI: body mass index, SD: standard deviation } \\
\hline
\end{tabular}

side effects were manageable and most of them were of grade 1 and 2. Gastrointestinal side effects were the most frequent toxicities particularly nausea and vomiting followed by diarrhea. All the reported side effects showed insignificant variation between the 2 arms except for diarrhea. Celecoxib/FOLFIRI arm showed significantly lower incidence of diarrhea than FOLFIRI arm ( $12 \%$ versus $43 \% ; p=0.015)$. Cardiac toxicity was not reported in both arms. Only one case died in FOLFIRI arm. The number and percent of the observed side effects are outlined in Table 4.

Discussion. Chemotherapy is the backbone of CRC treatment. However, inherent drug resistance and chemotherapy-related side effects reduce its overall efficacy. Hence, new therapeutic options including COX-2 inhibitors are currently important aspects of clinical trials for improving clinical outcomes. ${ }^{13}$ 
Table 2 - Biological markers in the 2 study groups at baseline and after 6 cycles.

\begin{tabular}{|c|c|c|c|c|c|}
\hline \multirow[t]{2}{*}{ Parameters } & \multicolumn{2}{|c|}{ Control group $(\mathrm{n}=28)$} & \multicolumn{2}{|c|}{ Celecoxib group $(n=26)$} & \multirow[t]{2}{*}{$P_{I}$-value } \\
\hline & Mean \pm SD & $P$-value & Mean \pm SD & $P$-value & \\
\hline \multicolumn{6}{|l|}{ CEA } \\
\hline $\begin{array}{l}\text { At baseline } \\
\text { After } 6 \text { cycles }\end{array}$ & $\begin{array}{c}103.02 \pm 31.22 \\
90.09 \pm 32.62\end{array}$ & 0.097 & $\begin{array}{l}112 \pm 35.23 \\
28.8 \pm 9.76\end{array}$ & $<0.001^{*}$ & $\begin{array}{c}0.338 \\
<0.001^{*}\end{array}$ \\
\hline \multicolumn{6}{|l|}{ CA19.9 } \\
\hline $\begin{array}{l}\text { At baseline } \\
\text { After } 6 \text { cycles }\end{array}$ & $\begin{array}{l}159.20 \pm 39.68 \\
139.50 \pm 51.04\end{array}$ & 0.069 & $\begin{array}{l}170.70 \pm 54.7 \\
47.19 \pm 16.33\end{array}$ & $<0.001^{*}$ & $\begin{array}{r}0.379 \\
<0.001^{*}\end{array}$ \\
\hline \multicolumn{6}{|l|}{$V E G F(n g / L)$} \\
\hline $\begin{array}{l}\text { At baseline } \\
\text { After } 6 \text { cycles }\end{array}$ & $\begin{array}{l}2220.95 \pm 427.04 \\
2261.15 \pm 310.08\end{array}$ & 0.669 & $\begin{array}{l}2281.97 \pm 573.35 \\
1533.09 \pm 368.29\end{array}$ & $<0.001^{*}$ & $\begin{array}{c}0.658 \\
<0.001^{*}\end{array}$ \\
\hline \multicolumn{6}{|l|}{ CXCL5 $(\mathrm{pg} / \mathrm{ml})$} \\
\hline $\begin{array}{l}\text { At baseline } \\
\text { After } 6 \text { cycles }\end{array}$ & $\begin{array}{l}76.39 \pm 10.86 \\
93.43 \pm 21.04\end{array}$ & $0.002^{*}$ & $\begin{array}{l}82.46 \pm 17.90 \\
51.19 \pm 13.79\end{array}$ & $<0.001^{*}$ & $\begin{array}{c}0.135 \\
<0.001^{*}\end{array}$ \\
\hline \multicolumn{6}{|l|}{$s F A S(n g / m l)$} \\
\hline $\begin{array}{l}\text { At baseline } \\
\text { After } 6 \text { cycles }\end{array}$ & $\begin{array}{c}46.86 \pm 10.12 \\
48.51 \pm 8.16\end{array}$ & 0.472 & $\begin{array}{l}43.21 \pm 7.07 \\
65.1 \pm 18.02\end{array}$ & $<0.001^{*}$ & $\begin{array}{c}0.134 \\
<0.001^{*}\end{array}$ \\
\hline \multicolumn{6}{|l|}{$s F A S L(n g / m l)$} \\
\hline $\begin{array}{l}\text { At baseline } \\
\text { After } 6 \text { cycles }\end{array}$ & $\begin{array}{l}15.22 \pm 3.89 \\
16.51 \pm 3.79\end{array}$ & 0.155 & $\begin{array}{c}15.37 \pm 4.09 \\
9.24 \pm 2.94\end{array}$ & $<0.001^{*}$ & $\begin{array}{c}0.892 \\
<0.001^{*}\end{array}$ \\
\hline \multicolumn{6}{|l|}{ sFAS/sFASL ratio } \\
\hline $\begin{array}{l}\text { At baseline } \\
\text { After } 6 \text { cycles }\end{array}$ & $\begin{array}{c}3.169 \pm 0.63 \\
3.03 \pm 0.61\end{array}$ & 0.309 & $\begin{array}{c}3.059 \pm 1.28 \\
8.17 \pm 4.77\end{array}$ & $<0.001^{*}$ & $\begin{array}{c}0.892 \\
<0.001^{*}\end{array}$ \\
\hline
\end{tabular}

Survival proportions: Survival of OS

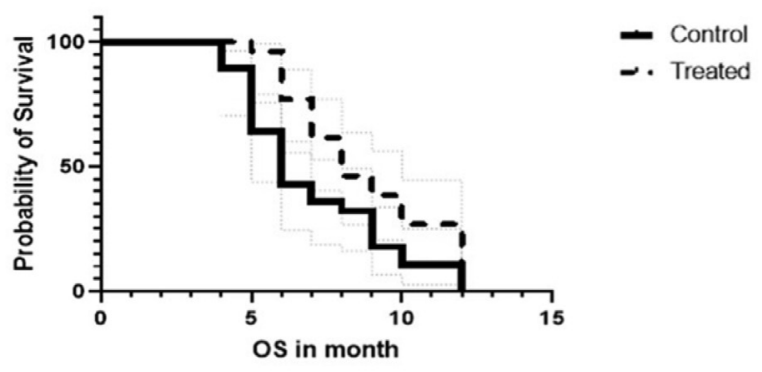

Figure 2 - One-year overall survival (OS) for the control group (FOLFIRI only) versus treated (FOLFIRI + celecoxib) group.

Participants in the present study were treated with the traditional FOLFIRI regimen combined with celecoxib. The efficacy and side effects of this combination were assessed by comparison with patients treated with the FOLFIRI regimen alone.

The addition of celecoxib to FOLFIRI regimen induced a statistically significant increase in both ORR and DCR using the RECIST criteria. These findings are compatible with a former finding that showed a statistically significant increase in short-term efficacy, response rate, and DCR after adding celecoxib to chemotherapy in different types of cancer. ${ }^{14,15}$ Furthermore, a previous report demonstrated that, the addition of celecoxib to preoperative chemo-radiation for patients with locally advanced rectal cancer resulted in a better response $(61 \%)$ when compared with patients treated with placebo $(35 \%){ }^{16}$

Angiogenesis represents a central pathway for tumor metastasis. Angiogenesis is a consequence of the imbalance between positive and negative angiogenic regulators released by both tumor and host cells. ${ }^{17}$ Vascular endothelial growth factor is a potent angiogenic factor which exerts several effects on tumor growth including endothelial cell proliferation and survival, stimulation of neovascularization, and suppression of host immune response. ${ }^{18}$ Our data demonstrated that, celecoxib/FOLFIRI arm induced a statistically significant decrease in serum level of VEGF as compared to FOLFIRI regimen. This result indicates that, celecoxib may act as anti-angiogenic agent. The inhibition of angiogenesis translated by decreased VEGF level by the concomitant use of celecoxib with FOLFIRI may be attributed to the ability of celecoxib to inhibit COX-2 enzyme with subsequent decreased 
Table 3 - Objective response rates of the 2 groups after 6 cycles and follow up after one year.

\begin{tabular}{|c|c|c|c|}
\hline \multirow[t]{2}{*}{ Tumor response } & Control group $(n=28)$ & Celecoxib group $(n=26)$ & \multirow[t]{2}{*}{$P$-value } \\
\hline & \multicolumn{2}{|c|}{ n $(\%)$} & \\
\hline CR & $0(0)$ & $1(3.9)$ & \\
\hline PR & $5(17.9)$ & $15(57.7)$ & \\
\hline SD & $6(21.4)$ & $5(19.2)$ & $0.001^{*}$ \\
\hline PD & $17(60.7)$ & $5(19.2)$ & \\
\hline ORR & $5(17.9)$ & $16(61.6)$ & $0.001^{*}$ \\
\hline DCR & $11(39.3)$ & $21(80.8)$ & 0.002 \\
\hline Median progression free survival & 23 week & 30 week & $0.004^{*}$ \\
\hline Median overall survival & 8 months & 12 months & $0.042^{*}$ \\
\hline Precentage of one year overall survival & $25 \%$ & $57.7 \%$ & $0.015^{*}$ \\
\hline \multicolumn{4}{|c|}{$\begin{array}{l}\text { CR: complete response, PR: partial response, SD: stable disease, PD: progressive disease, ORR: objective response rate, } \\
\text { DCR: disease control rate, in CR disappearance of all target lesions, in PR at least a } 30 \% \text { decrease in the sum of the } \\
\text { longest diameters of target lesions, in PD at least a } 20 \% \text { increase in the sum of diameters of target lesions, in SD neither } \\
\text { sufficient shrinkage to qualify for PR nor sufficient increase to qualify for PD, ORR is the sum of CR and PR, DCR is } \\
\text { the sum of CR, PR, SD. significant difference }(p<0.05)\end{array}$} \\
\hline
\end{tabular}

Table 4 - The reported adverse effects by the 2 study groups.

\begin{tabular}{|c|c|c|c|c|c|c|c|c|c|c|c|c|}
\hline \multirow[t]{3}{*}{ Side effects } & \multicolumn{5}{|c|}{ Control group $(n=28)$} & \multicolumn{5}{|c|}{ Celecoxib group $(n=26)$} & \multirow[t]{3}{*}{$P$-value ${ }^{\dagger}$} & \multirow[t]{3}{*}{$P$-value } \\
\hline & \multirow[b]{2}{*}{ I } & \multicolumn{3}{|c|}{ Grades } & \multirow[b]{2}{*}{$\begin{array}{l}\text { Total } \\
\text { n (\%) }\end{array}$} & \multicolumn{5}{|c|}{ Grades } & & \\
\hline & & II & III & IV & & I & II & III & IV & $\begin{array}{l}\text { Total } \\
\text { n (\%) }\end{array}$ & & \\
\hline Neutropenia & 3 & 3 & 3 & 2 & $11(39)$ & 3 & 2 & 1 & 1 & $7(27)$ & 0.487 & 0.396 \\
\hline Leukopenia & 3 & 3 & 2 & 1 & $9(32)$ & 2 & 2 & 1 & 1 & $6(23)$ & 0.918 & 0.550 \\
\hline Nausea/vomiting & 5 & 4 & 4 & 3 & $16(57)$ & 4 & 4 & 2 & 1 & $11(42)$ & 0.449 & 0.414 \\
\hline Diarrhea & 3 & 4 & 3 & 2 & $12(43)$ & 2 & 1 & 0 & 0 & $3(12)$ & 0.130 & $0.015^{*}$ \\
\hline Mucositis & - & - & - & - & - & - & - & - & - & - & & - \\
\hline CVS & - & - & - & - & - & - & - & - & - & - & & - \\
\hline Infection & 2 & 3 & 0 & 0 & $5(18)$ & 2 & 0 & 0 & 0 & $2(8)$ & 0.147 & 0.423 \\
\hline
\end{tabular}

CVS: cardiovascular, ${ }^{\dagger}$ value to compare grades (Chi square for trend), ${ }^{\ddagger}$ value to compare totals ( Fisher exact test), "significant difference ( $p<0.05$ )

prostaglandin E2 which plays a critical role in the production of VEGF. ${ }^{19}$ Our data comes in parallel with a previous reported hypothesized study that, higher serum VEGF was associated with poor prognosis in patients with CRC and hepatic metastasis. ${ }^{20}$ Furthermore, it has been postulated that, the concomitant use of celecoxib with standard chemotherapy in patients with gastric cancer resulted in a decline in VEGF level. ${ }^{21}$

Epithelial-derived neutrophil activating peptide 78 (ENA78/CXCL5) is a member of the CXC-type chemokine family, that plays a critical role in tumorigeneses and cancer progression. Epithelialderived neutrophil activating peptide 78 is up-regulated in tumor tissues than para-cancerous tissues and it is usually correlated with advanced tumor stages and poor prognosis. $^{22}$ Our results demonstrated that, CXCL5 serum level was elevated in all patients with metastatic colorectal and its level tended to be significantly decreased in celecoxib/FOLFIRI arm as compared to FOLFIRI regimen. In this context, our result may suggest that celecoxib could counteract cancer progression through decreasing CXCL5 serum level. This suggestion was based on the notion that, CXCL5 promotes angiogenesis through activation of nuclear factor kappa-light-chain-enhancer (serine/threonine kinase $[\mathrm{AKT}] / \mathrm{NF}-\mathrm{kB}$ ) which is one of the most important mechanisms implicated in inflammation, tumorigenesis and cell proliferation. ${ }^{23}$ Celecoxib was reported to inhibit NF-kB via amplification of IkB inhibitor protein with subsequent decline in CXCL5 serum level and to block AKT/NF-kB pathway involved in angiogenesis and tumorigenesis. ${ }^{24}$ Our favorable result concerning the effect of celecoxib on CXCL5 comes in agreement with a previous study reported that, elevated CXCL5 level is correlated with colorectal metastases and poor prognosis. ${ }^{22}$ 
Factor-related apoptosis or APO-1 or CD95 belongs to a subgroup of the tumor necrosis factor receptor (TNF-R) family. An intracellular death domain binds to its physiological ligand, FASL or CD95L, and triggers apoptosis (extrinsic apoptotic pathway). Factorrelated apoptosis can exist as a cell surface or soluble protein. The pro-apoptotic role for FAS and FASL is well known, but conflicting data about the function of the soluble form still exists. Anti-apoptotic or proapoptotic function has been suggested for the soluble form. The formation of homotrimers between soluble forms induces a pro-apoptotic effect. Conversely, the formation of heterotrimers, when binding to transmembrane FAS receptor, fails to trigger apoptosis and promote calcium-dependent cell migration, invasion, and metastasis. ${ }^{25}$ In the present study, the baseline serum levels of sFASL were elevated in both arms secondary to activation of matrix metalloproteinase including matrix metalloproteinase-7 during the advanced stages of the disease. ${ }^{26}$ An increase in sFASL exerts anti-apoptotic and immune surveillance actions. The administration of celecoxib with FOLFIRI produced significant elevation of sFAS and significant decline of sFASL levels. Furthermore, the addition of celecoxib to FOLFIRI provoked a 2.7-fold increase sFAS/FASL ratio $(p<0.001)$. These findings may reflect the ability of celecoxib to inhibit COX-2, up-regulate FAS expression, and downregulate FASL expression. ${ }^{27}$ Celecoxib may have a role in inducing apoptosis since increased FAS was reported to enhance killer immune cell function against tumor cells and to inhibit tumor cell immunity. ${ }^{28}$ Furthermore, celecoxib may enhance chemo-sensitivity. A previous study indicated that patients with CRC displayed an increment (1.2-fold) in sFAS/sFASL ratio following chemotherapy (chemo-sensitivity). ${ }^{29}$ However, sFAS/sFASL ratio tended to be decreased during the treatment course with chemotherapy secondary to the acquired chemoresistance.

Celecoxib was well tolerated as translated by the absence of significant variations in the incidence of side effects between the 2 arms. This result is consistent with previous clinical studies conducted on patients with $\mathrm{CRC}$ and showed that, celecoxib was well tolerated at higher $(800 \mathrm{mg} /$ day $)$ and lower doses $(400 \mathrm{mg} /$ day $) .{ }^{10,13}$ Additionally, the current data are similar to previous report postulated study that, celecoxib therapy in conjunction with chemo-radiation did not cause additional toxicity as compared to placebo.

The impact of celecoxib on survival indices remains unclear. Previous studies reported clinically meaningful benefits, yet other studies reported a lack of such benefits. ${ }^{11,13}$ During the current study, the PFS and one-year OS showed significant improvement in celecoxib/FOLFIRI arm as compared to FOLFIRI arm, a result comes in parallel with a previously reported finding.

Overall, the present study indicates that celecoxib is well tolerated and seems efficacious as adjuvant therapy to FOLFIRI regimen in patients with metastatic CRC as translated by the improvement of ORR, DCR, and serum levels of the biological markers involved in carcinogenesis (VEGF, CXCL5, sFASL, and sFAS/FASL ratio) with enhancement of both PFS and OS.

The points of strength in the present study includes: its randomized controlled design; relatively good follow-up period (one year); and its superiority to evaluate the serum level of CXCL5 in patients with metastatic CRC.

Study limitations. The small sample size and the administration of a low dose of celecoxib without testing higher doses represent the main limitation for the present study. Thus, further large scale studies are still necessary. Another limitation of the current study is being open label.

In conclusion, the addition of celecoxib to FOLFIRI produced significant declines in serum levels of the biomarkers for angiogenesis VEGF, sFAS and sFASL, and metastasis CXCL5 which was associated with significant increase in sFAS/FASL ratio indicating chemo-sensitivity. Furthermore, the addition of celecoxib to FOLFIRI produced a significant increase in both ORR and DCR. The current research suggests that, celecoxib may represent an effective and safe adjuvant gent to chemotherapy for patients with metastatic CRC. However, these promising results warrant further investigations.

Acknowledgment. The authors gratefully acknowledge the oncologists and the radiologists at Oncology Department, Tanta University Hospital, Tanta, Egypt, for their valuable help. We also would like to thank the participants for their participation and cooperation and EKB enago (www.ekb.eg/ar/nature-esearch) for English language editing.

\section{References}

1. Siegel RL, Miller KD, Goding Sauer A, Fedewa SA, Butterly LF, Anderson JC, et al. Colorectal cancer statistics, 2020. CA Cancer J Clin 2020; 70: 145-164.

2. Woo IS, Jung YH. Metronomic chemotherapy in metastatic colorectal cancer. Cancer Lett 2017; 400: 319-324.

3. Buzzelli JN, Ouaret D, Brown G, Allen PD, Muschel RJ. Colorectal cancer liver metastases organoids retain characteristics of original tumor and acquire chemotherapy resistance. Stem Cell Res 2018; 27: 109-120. 
4. Shen Y, Tong M, Liang Q, Guo Y, Sun HQ, Zheng W, et al. Epigenomics alternations and dynamic transcriptional changes in responses to 5-fluorouracil stimulation reveal mechanisms of acquired drug resistance of colorectal cancer cells. Pharmacogenomics J 2018; 18: 23-28.

5. Pushpakom S, Iorio F, Eyers PA, Escott KJ, Hopper S, Wells A, et al. Drug repurposing: progress, challenges and recommendations. Nat Rev Drug Discov 2019; 18: 41-58.

6. Greten FR, Grivennikov SI. Inflammation and cancer: triggers, mechanisms, and consequences. Immunity 2019; 51: 27-41.

7. Lee JS, Kim HS, Hahm KB, Surh YJ. Effects of genetic and pharmacologic inhibition of COX-2 on colitis-associated carcinogenesis in mice. J Cancer Prev 2020; 25: 27-37.

8. Tudor DV, Bâldea I, Olteanu DE, Fischer-Fodor E, Piroska V, Lupu M, et al. Celecoxib as a valuable adjuvant in cutaneous melanoma treated with trametinib. Int J Mol Sci 2021; 22: 4387.

9. Tołoczko-Iwaniuk N, Dziemiańczyk-Pakieła D, Nowaszewska BK, Celińska-Janowicz K, Miltyk W. Celecoxib in cancer therapy and prevention - review. Curr Drug Targets 2019; 20: 302-315.

10. Chen EY, Blanke CD, Haller DG, Benson AB, Dragovich T, Lenz HJ, et al. A phase II study of celecoxib with irinotecan, 5-fluorouracil, and leucovorin in patients with previously untreated advanced or metastatic colorectal cancer. Am J Clin Oncol Cancer Clin Trials 2018; 41: 1193-1198.

11. Meyerhardt JA, Shi Q, Fuchs CS, Meyer J, Niedzwiecki D, Zemla T, et al. Effect of celecoxib vs placebo added to standard adjuvant therapy on disease-free survival among patients with stage III colon cancer: the CALGB/SWOG 80702 (alliance) randomized clinical trial. JAMA 2021; 325: 1277-1286.

12. Eisenhauer EA, Therasse P, Bogaerts J, Schwartz LH, Sargent D, Ford R, et al. New response evaluation criteria in solid tumours: revised RECIST guideline (version 1.1). Eur J Cancer 2009; 45: 228-247.

13. Hammond WA, Swaika A, Mody K. Pharmacologic resistance in colorectal cancer: a review. Ther Adv Med Oncol 2016; 8: 57-84.

14. Yi L, Zhang W, Zhang H, Shen J, Zou J, Luo P, et al. Systematic review and meta-analysis of the benefit of celecoxib in treating advanced non-small-cell lung cancer. Drug Des Devel Ther 2018; 12: 2455-2466.

15. Guo Q, Li Q, Wang J, Liu M, Wang Y, Chen Z, et al. A comprehensive evaluation of clinical efficacy and safety of celecoxib in combination with chemotherapy in metastatic or postoperative recurrent gastric cancer patients: a preliminary, three-center, clinical trial study. Medicine (Baltimore) 2019; 98: e16234.

16. Zhou X, Wang X, Zhao Y, Yi C. The role of celecoxib for colorectal cancer treatment: a systematic review. Transl Cancer Res 2018; 7: 1527-1536.

17. Larionova I, Kazakova E, Gerashchenko T, Kzhyshkowska J. New angiogenic regulators produced by TAMs: perspective for targeting tumor angiogenesis. Cancers (Basel) 2021; 13: 3253.
18. Saberi-Karimian M, Katsiki N, Caraglia M, Boccellino M, Majeed M, Sahebkar A. Vascular endothelial growth factor: an important molecular target of curcumin. Crit Rev Food Sci Nutr 2019; 59: 299-312.

19. Xie C, Xu X, Wang X, Wei S, Shao L, Chen J, et al. Cyclooxygenase-2 induces angiogenesis in pancreatic cancer mediated by prostaglandin $\mathrm{E}_{2}$. Oncol Lett 2018; 16: 940-948.

20. Divella R, Daniele A, DE Luca R, Simone M, Naglieri E, Savino E, et al. Circulating levels of VEGF and CXCL1 are predictive of metastatic organotropismin in patients with colorectal cancer. Anticancer Res 2017; 37: 4867-4871.

21. Li S, Jiang M, Wang L, Yu S. Combined chemotherapy with cyclooxygenase-2 (COX-2) inhibitors in treating human cancers: Recent advancement. Biomed Pharmacother 2020; 129: 110389.

22. Zhao J, Ou B, Han D, Wang P, Zong Y, Zhu C, et al. Tumorderived CXCL5 promotes human colorectal cancer metastasis through activation of the ERK/Elk-1/Snail and AKT/ GSK3 $\beta / \beta$-catenin pathways. Mol Cancer 2017; 16: 70.

23. Chen C, Xu ZQ, Zong YP, Ou BC, Shen XH, Feng H, et al. CXCL5 induces tumor angiogenesis via enhancing the expression of FOXD1 mediated by the AKT/NF- $\mathrm{KB}$ pathway in colorectal cancer. Cell Death Dis 2019; 10: 178.

24. Zuo C, Hong Y, Qiu X, Yang D, Liu N, Sheng X, et al. Celecoxib suppresses proliferation and metastasis of pancreatic cancer cells by down-regulating STAT3/NF-kB and L1CAM activities. Pancreatology 2018; 18: 328-333.

25. Guégan JP, Ginestier C, Charafe-Jauffret E, Ducret T, Quignard JF, Vacher P, et al. CD95/Fas and metastatic disease: what does not kill you makes you stronger. Semin Cancer Biol 2020; 60: 121-131.

26. Shantha Kumara H, Miyagaki H, Herath SA, Pettke E, Yan X, Cekic V, et al. Plasma MMP-2 and MMP-7 levels are elevated first month after surgery and may promote growth of residual metastases. World J Gastrointest Oncol 2021; 13: 879-892.

27. Li Q, Peng J, Liu T, Zhang G. Effects of celecoxib on cell apoptosis and Fas, FasL and Bcl-2 expression in a BGC-823 human gastric cancer cell line. Exp Ther Med 2017; 14: 1935-1940.

28. Strizova Z, Kuchar M, Capkova L, Komarc M, Skrivan J, Bartunkova J, et al. Fas-Fas ligand interplay in the periphery of salivary gland carcinomas as a new checkpoint predictor for disease severity and immunotherapy response. Biomedicines 2021; 9: 402.

29. Peter ME, Hadji A, Murmann AE, Brockway S, Putzbach W, Pattanayak A, et al. The role of CD95 and CD95 ligand in cancer. Cell Death Differ 2015; 22: 549-559. 